Mathematical Modelling and Analysis

Volume 5, 2000, PAGes 133-142

(C) 2000 Technika

\title{
DIFFERENCE SCHEMES OF HIGH ORDER ACCURACY FOR MATHEMATICAL PHYSICS PROBLEMS IN ARBITRARY DOMAINS
}

\author{
P.P. MATUS, A.N. ZYL \\ Institute of Mathematics of NASB \\ Surganov St. 11, 220072 Minsk, Belarus \\ e-mail matus@im.bas-net.by, dns@im.bas-net.by
}

Received August 9, 1999; revised October 29, 1999

\begin{abstract}
In the present paper the difference schemes of high order accuracy for two-dimensional equations of mathematical physics in an arbitrary domain are constructed. The computational domain is covered by a uniform rectangular grid. The second order accuracy of local approximation by spatial variables is achieved near-boundary nodes. No increase of a standard grid scheme template is required. Apriori estimates of the stability are obtained.
\end{abstract}

\section{INTRODUCTION}

Various approaches are used in numerical solution of boundary problems in an arbitrary computation domain. The computation domain may be covered by a uniform rectangular grid, and the difference scheme is constructed on the essentially non-uniform template. Usually such schemes have the second order of accuracy in the maximum norm, but the local error of approximation near the boundary has the first order, or even the difference scheme does not approximate the differential problem [1]. A high order of approximation near the boundary is important for a number of problems. For example, it is often necessary to compute the normal derivative of the solution at the whole boundary of computational area or at the part of it.

Second-order accuracy schemes on irregular rectangular grids were constructed in [2] - [4]. Such algorithms were constructed using approximations of the equation at a specially selected point. In $[5 ; 6]$ on the basis of these 
methods a high-order approximation scheme was constructed for the elliptic equation in an arbitrary computation area. In [7] a monotonicity of this scheme was proved by means of the principle of maximum for a wide class of areas. In the present paper the difference schemes of the second-order accuracy approximation are considered for elliptic and parabolic equations in an arbitrary domain. In the case of rectangular domain such schemes degenerate to standard schemes [2] - [4]. The a priori estimates of the stability and convergence are obtained for the algorithms. The tests results demonstrate a high effectiveness of the proposed methods.

\section{CONSTRUCTION OF THE GRID IN AN ARBITRARY DO- MAIN}

Let $\Omega$ be an arbitrary two-dimensional domain, and $\Gamma$ is a boundary. Let us introduce in $\bar{\Omega}$ the uniform rectangular grid $\omega_{0}$ with the steps $H_{k}$ for the dimension $x_{k}, k=1,2$. Assume that the computational domain is convex and the grid is connected.

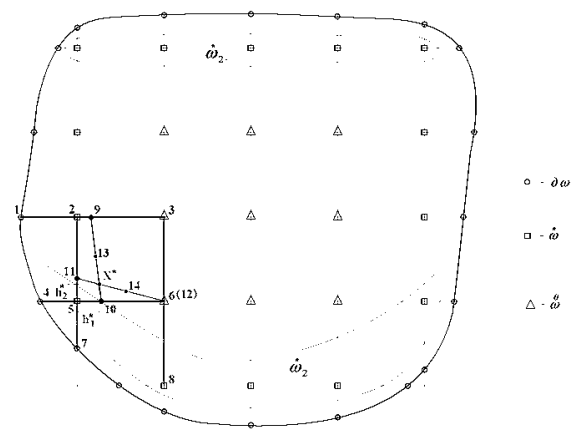

Figure 1. The computation grid $\omega_{0}$.

Let $\gamma_{h}$ be a set of boundary nodes which are generated by intersection points of the lines $x_{k}=$ const, $k=1,2$ with the boundary $\partial \Omega$. Let $\omega_{h}=$ $\left\{\mathbf{x} \mid \mathbf{x} \in \Omega \cap \omega_{0}\right\}$ be a set of interior nodes. We also define the subset of nearboundary nodes $\stackrel{*}{\omega}$ and the subset of interior nodes $\stackrel{\circ}{\omega}$. We denote by $\stackrel{*}{\omega}_{k}$ a set of near-boundary nodes in the direction $x_{k}$. Let $\gamma_{k}^{+}$be a set of right boundary nodes and $\gamma_{k}^{-}$be a set of left boundary nodes in the direction $x_{k}$. We denote by $\stackrel{*}{\omega}_{k \pm}$ the sets of left and right near-boundary nodes, respectively. Let us

suppose that the difference grid is sufficiently detailed, i.e. for any $\mathbf{x} \in \stackrel{*}{\omega}$ and every $k=1,2$ either $x^{+1_{k}}$ or $x^{-1_{k}}$ is not a point on $\gamma$.

We use the following notation of the theory of difference schemes [1]:

$$
\mathbf{x}=\mathbf{x}_{i_{1}, i_{2}}=\left(x_{1}^{i_{1}}, x_{2}^{i_{2}}\right), \quad x_{k}^{i_{k}}=x_{k}^{i_{k}-1}+h_{k}^{i_{k}},
$$




$$
\begin{gathered}
h_{k}=h_{k}^{i_{k}}, \quad h_{k+}=h_{k}^{i_{k}+1}, \quad \hbar_{k}=\frac{1}{2}\left(h_{k+}+h_{k}\right), \\
y=y(\mathbf{x}), \quad y^{+1_{1}}=y\left(x_{1}+h_{1+}, x_{2}\right), \quad y^{-1_{1}}=y\left(x_{1}-h_{1}, x_{2}\right), \\
y^{+1_{2}}=y\left(x_{1}, x_{2}+h_{2+}\right), \quad y^{-1_{2}}=y\left(x_{1}, x_{2}-h_{2}\right), \\
y_{x_{k}}=\frac{y^{+1_{k}}-y}{h_{k+}}, \quad y_{\bar{x}_{k}}=\frac{y-y^{-1_{k}}}{h_{k}}, \quad y_{\bar{x}_{k} \hat{x}_{k}}=\frac{y_{x_{k}}-y_{\bar{x}_{k}}}{\hbar_{k}}, \quad k=1,2 .
\end{gathered}
$$

We use a standard approximation of the Laplace operator at the interior nodes [1]:

$$
\Delta u \sim u_{\bar{x}_{1} \hat{x}_{1}}+u_{\bar{x}_{2} \hat{x}_{2}} .
$$

In order to determine the template of the difference scheme at near-boundary nodes, the difference operator is defined as follows

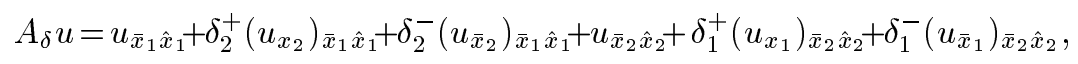

where $\delta_{k}^{ \pm}=\frac{1}{2}\left(\tilde{h}_{k} \pm\left|\tilde{h}_{k}\right|\right), \quad \tilde{h}_{k}=\frac{1}{3}\left(h_{k+}-h_{k}\right), \quad \bar{x}_{k}=x_{k}+\tilde{h}_{k}, \quad k=1,2$.

This operator approximates the Laplace operator with the second order in the case of a rectangular area which is covered by a rectangular non-uniform grid [5], [6]. The operator (1.1) is called the template operator. The domain of its definition prescribes the template of a difference scheme at the nearboundary nodes. On the basis of this operator a difference scheme for an arbitrary domain is developed. It is shown in [5] that this operator approximates the Laplace operator with the second order at the point $\mathbf{x}^{*}=\left(x_{1}^{*}, x_{2}^{*}\right)$, $h_{k}^{*}=x_{k}^{*}-x_{k}, k=1,2$. The corresponding eight-point template is shown in fig. 1.

Let us define the following grid operators:

$$
\begin{gathered}
A y=A_{1} y+A_{2} y=-y_{\bar{x}_{1} \hat{x}_{1}}-y_{\bar{x}_{2} \hat{x}_{2}}, \\
A_{0} y=A_{0}^{1} y+A_{0}^{2} y, \quad A_{0}^{k} y=\left\{\begin{array}{cc}
\delta_{k}^{+} A_{3-k} y_{x_{k}}, & h_{k}^{*}>0, \\
0, & h_{k}^{*}=0, \\
\delta_{k}^{-} A_{3-k} y_{\bar{x}_{k}}, & h_{k}^{*}<0,
\end{array} \quad k=1,2,\right. \\
A_{\delta}=A+A_{0},\left.\quad y\right|_{\gamma_{h}}=0 .
\end{gathered}
$$

Let $\mathcal{H}$ be a linear Hilbert space consisting of the grid functions, $y_{n}=y_{n}(\mathbf{x})$, which are given on $\bar{\omega}_{h}$ and are equal to zero on the boundary. In $\mathcal{H}$ let define the scalar product $\left(v_{n}, y_{n}\right)=\sum_{\mathbf{x} \in \omega_{h}} \hbar_{1} \hbar_{2} v_{n}(\mathbf{x}) y_{n}(\mathbf{x})$ and the norm $\|y\|^{2}=(y, y)$. Let $\mathcal{H}_{A}, A=A^{*}>0$ be a Hilbert space consisting of the elements from $\mathcal{H}$ with the scalar product and the norm

$$
\left.\left.\|y\|_{A}^{2}=(A y, y)=\| y_{\bar{x}_{1}}\right]\left.\right|^{2}+\| y_{\bar{x}_{2}}\right]\left.\right|^{2},
$$




$$
\left.\| y_{\bar{x}_{k}}\right]\left.\right|^{2}=\sum_{\mathbf{x} \in \omega_{k}^{+}} h_{k} \hbar_{3-k} y_{\bar{x}_{k}}^{2}, \quad k=1,2,
$$

where $\omega_{k}^{+}=\omega \cup \gamma_{k}^{+}$.

Lemma 1.1. The following estimate is valid:

$$
\left\|A_{0} y\right\| \leq \frac{2}{3}\|A y\|
$$

\section{DIFFERENCE SCHEME FOR THE ELLIPTIC EQUATION}

In this section we consider the Dirichlet problem for the two-dimensional Poisson equation in an arbitrary domain $\Omega$ :

$$
\begin{aligned}
& \sum_{k=1}^{2} \frac{\partial^{2} u}{\partial x_{k}^{2}}=-f(\mathbf{x}), \quad \mathbf{x}=\left(x_{1}, x_{2}\right) \in \Omega, \\
& u(\mathbf{x})=g(\mathbf{x}), \quad \mathbf{x} \in \partial \Omega .
\end{aligned}
$$

We develop the finite-difference scheme, which approximates the differential problem $(2.1),(2.2)$ of the second order with local approximation at the nearboundary nodes.

Using (1.1) we get the difference scheme

$$
A_{\delta} y=-f\left(x_{1}^{*}, x_{2}^{*}\right), \quad \mathbf{x} \in \stackrel{*}{\omega}
$$

where

$$
\delta_{k}^{ \pm}=\frac{1}{2}\left(h_{k}^{*} \pm\left|h_{k}^{*}\right|\right), \quad \bar{x}_{k}=x_{k}^{*}=x_{k}+h_{k}^{*}, \quad k=1,2 .
$$

In the case of rectangular non-uniform grid this scheme coincides with the finite-difference scheme of the second-order accuracy [2] - [4]; in the case of the regular rectangular grid it degenerates to the well-known scheme, which is defined on the five-point template.

In order to apply the maximum principle to the scheme (2.3), we must reduce it to the canonical form [1]:

$$
\alpha(\mathbf{x}) y(\mathbf{x})=\sum_{\xi \in \mathcal{M}^{\prime}(\mathbf{x})} \beta(\mathbf{x}, \xi) y(\xi)+\varphi(\mathbf{x}), \quad \mathbf{x} \in \omega .
$$

It is necessary to satisfy the following conditions for the coefficients:

$$
\alpha(\mathbf{x})>0, \quad \beta(\mathbf{x}, \xi)>0, \quad \alpha(\mathbf{x})-\sum_{\xi \in \mathcal{M}^{\prime}(\mathbf{x})} \beta(\mathbf{x}, \xi) \geq 0, \quad \mathbf{x} \in \omega,
$$

where $\mathcal{M}^{\prime}(\mathbf{x})=\mathcal{M}(\mathbf{x}) \backslash\{\mathbf{x}\}, \mathcal{M}(\mathbf{x})$ is the scheme template. 
Lemma 2.1. Let the conditions of the positivity of coefficients (2.5) are fulfilled for all $\mathrm{x} \in \omega$. Then the difference scheme (2.3), (2.4) is stable with respect to the (2.3), (2.4) right side and the boundary conditions, and the following estimate is valid:

$$
\|y\|_{C(\omega)} \leq c_{0}\|\varphi\|_{C(\omega)}+\|\mu\|_{C(\gamma)}, \quad c_{0}=\text { const }>0 .
$$

The proof is similar to one given in [3].

Let $z_{i_{1} i_{2}}=y_{i_{1} i_{2}}-u\left(x_{1}^{i_{1}}, x_{2}^{i_{2}}\right)$, where $y$ is the solution of the difference problem (2.3) and $u\left(x_{1}, x_{2}\right)$ is the solution of the differential problem (2.1), (2.2). Substituting $y=z+u$ into (2.3), we obtain the equation

$$
A_{\delta} z=-\psi, \quad \mathbf{x} \in \omega, \quad z(\mathbf{x})=0, \quad \mathbf{x} \in \gamma
$$

Here $\psi(\mathbf{x})=A_{\delta} u+f\left(\mathbf{x}^{*}\right)$ is a truncation error of the scheme. If conditions (2.5) are fulfilled, then using a priori estimates of stability and approximation error we have

$$
\|z\|_{C(\omega)} \leq M\left(h_{1}^{2}+h_{2}^{2}\right),
$$

where $M$ is a constant, which does not depend on $h_{1}, h_{2}$.

Theorem 2.1. Let the conditions of Lemma 2.1 are fulfilled for all $\mathrm{x} \in \omega$. The solution of the difference scheme (2.3), (2.4) converges to the solution of differential problem (2.1) and the estimate (2.7) is valid.

The conditions (2.5) are always fulfilled for seven-point templates (e.g., $h_{\alpha}=h_{\alpha+}=H$; see fig. 2a), and for some eight-point templates (in our case under conditions $h_{1}^{+1_{2}}=H$ and $h_{2}^{+1_{1}}=H$; see fig. 2b) [7]. It is also easy to

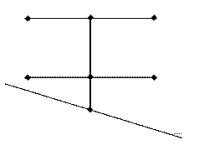

a

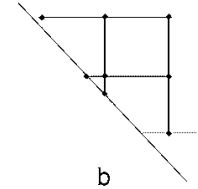

b

Figure 2. Seven-point templates.

show that conditions (2.5) are fulfilled without limitations on the grid steps for some types of polygons. E. g., these conditions are always fulfilled for polygons that satisfy to condition

$$
\beta_{n}=0 \text { or } 2 / 3<\operatorname{tg} \beta_{n}<3 / 2, \quad n=1,2, \ldots, N,
$$


where $N$ is the number of its sides, $\beta_{n}$ is the slope angle of the $n$-th side with respect to the grid lines.

The maximum principle requires fulfillment of strong conditions shape of the on the domain $\Omega$ The method of energy inequalities allows us to obtain estimates without limitations on the domain shape.

Let us write the difference scheme (2.3), (2.4) as

$$
\begin{gathered}
A_{\delta} y=\varphi(\mathbf{x}), \\
y(\mathbf{x})=0, \quad \mathbf{x} \in \gamma,
\end{gathered}
$$

where $\varphi(\mathbf{x})=f\left(x_{1}^{*}, x_{2}^{*}\right), A_{\delta}=A+A_{0}$.

Theorem 2.2. The difference scheme (2.8), (2.9) is stable with respect to the right side, and the following estimate is valid:

$$
\|A y\| \leq 3\|\varphi\| .
$$

Proof We compute the scalar product of (2.8) with $A y$. We have

$$
(A y, A y)+\left(A_{0} y, A y\right)=(\varphi, A y)
$$

Using Lemma 1.1, we get $\left(A_{0} y, A y\right) \geq-\frac{2}{3}\|A y\|^{2}$. Let us estimate the scalar product $(\varphi, A y)$ as

$$
(\varphi, A y) \leq \frac{3}{2}\|\varphi\|^{2}+\frac{1}{6}\|A y\|^{2} .
$$

Combining the obtained inequalities and (2.10), we get $\frac{1}{6}\|A y\|^{2} \leq \frac{3}{2}\|\varphi\|^{2}$.

\section{DIFFERENCE SCHEME FOR A PARABOLIC EQUATION}

Let $\Omega$ be an arbitrary two-dimensional area with the boundary $\Gamma$. It is required to find the continuous function $u(\mathbf{x}, t), \mathbf{x}=\left(x_{1}, x_{2}\right)$, satisfying in $\bar{Q}_{T}=\bar{\Omega} \times$ $[0, T]$ the initial-boundary problem

$$
\begin{gathered}
\frac{\partial u}{\partial t}=L u+f(\mathbf{x}, t), \quad(\mathbf{x}, t) \in Q_{T}, \\
L u=\sum_{k=1}^{2} L_{k} u, \quad L_{k} u=\frac{\partial^{2} u}{\partial x_{k}^{2}}, \\
u(\mathbf{x}, 0)=u_{0}(\mathbf{x}), \quad \mathbf{x} \in \bar{\Omega},\left.\quad u\right|_{\partial Q_{T}}=\mu(\mathbf{x}, t), \quad \partial Q_{T}=\Gamma \times(0, T] .
\end{gathered}
$$

Further, we shall assume that a solution of the problem (3.1), (3.2) exists, it is unique and has all necessary bounded derivatives. 
Let us introduce a spatial-time grid in $\bar{Q}_{T}: \bar{\omega}=\hat{\bar{\omega}}_{h} \times \bar{\omega}_{\tau}, \quad \bar{\omega}_{\tau}=\left\{t_{n}=\right.$ $\left.n \tau, \quad n=0,1, \ldots, N_{0} ; \quad \tau N_{0}=T\right\}=\omega_{\tau} \cup\{T\}$.

Using the operator $A_{\delta}$ we construct the difference scheme of high-order approximation for the differential problem (3.1), (3.2). Thus the difference scheme may be written as

$$
y_{(\alpha) t}+A_{\delta} y^{(\sigma)}=f^{(\sigma)}\left(\mathbf{x}^{*}, t\right),
$$

where $y_{(\alpha)}=y+\sum_{k=1}^{2}\left\{\delta_{k}^{+} y_{x_{k}}+\delta_{k}^{-} y_{\bar{x}_{k}}\right\}$.

Let us determine the order of the approximation error of difference scheme (3.3). Substituting $z+u$ for $y$ into (3.3), we get the problem for the global $z$ :

$$
z_{(\alpha) t}+A_{\delta} z^{(\sigma)}=\psi^{(\sigma)}, \quad z(\mathbf{x}, 0)=0,\left.\quad z^{(\sigma)}\right|_{\gamma_{h}}=0,
$$

where $\psi=\psi_{1}+\psi_{2}$,

$$
\begin{gathered}
\psi_{1}=u_{(\alpha) t}-\frac{\partial u}{\partial t}\left(\mathbf{x}^{*}, t\right)=O\left(h^{2}+\tau\right), \\
\psi_{2}=A_{\delta} u^{(\sigma)}+L u\left(\mathbf{x}^{*}, t\right)=O\left(h^{2}+\tau\right), \\
h=\max _{\mathbf{x} \in \omega_{h}}\left\{h_{1}, h_{2}\right\} .
\end{gathered}
$$

Using (3.4), (3.5), we get the following estimate

$$
\max _{t \in \omega_{\tau}}\|\psi\|_{C} \leq c_{0}\left(h^{2}+\tau\right), \quad c_{0}=\text { const }>0
$$

where $\|\cdot\|_{C}=\max _{\mathbf{x} \in \omega_{h}}|\cdot|$. Consequently, the difference scheme (3.3) approximates the differential problem on the grid $\omega_{h}$ with the second order.

Let define the following operators

$$
\tilde{A}=\tilde{A}_{1}+\tilde{A}_{2}, \quad \tilde{A}_{k} y=\left\{\begin{array}{cc}
\delta_{k}^{+} y_{x_{k}}, & h_{k}^{*}>0, \\
0, & h_{k}^{*}=0, \\
\delta_{k}^{-} y_{\bar{x}_{k}}, & h_{k}^{*}<0,
\end{array} \quad k=1,2\right.
$$

Then the difference scheme (3.3) can be written in the canonical form

$$
\begin{gathered}
B y_{t}+A_{\delta} y=\varphi, \quad y_{0}=u_{0}, \quad \varphi=f^{(\sigma)}\left(\mathbf{x}^{*}, t\right), \\
B=D+\sigma \tau A_{\delta}, \quad D=E+\tilde{A} .
\end{gathered}
$$


Theorem 3.1. Let $\|\tilde{A} y\|^{2} \leq c_{1} \alpha^{2}(A y, y), c_{1}=$ const $>0,\left\|A_{0} y\right\|^{2} \leq(1-$ $\left.c_{2}\right)\|A y\|^{2}, c_{2}=$ const, $0<c_{2} \leq 1$. Then under the limitation

$$
\tau>\frac{c_{1} \alpha^{2}}{4(\sigma-0,5) \varepsilon_{1}}, \quad \sigma>0,5
$$

the following estimate

$$
\left\|y_{n+1}\right\|_{A}^{2} \leq\left\|u_{0}\right\|_{A}^{2}+\frac{1}{2 \varepsilon_{2}} \sum_{k=0}^{n} \tau\left\|\varphi_{k}\right\|^{2},
$$

holds for the difference scheme (3.6), where $\varepsilon_{1}, \varepsilon_{2}=$ const $>0, c_{2} \geq 2\left(\varepsilon_{1}+\varepsilon_{2}.\right)$

In order to obtain a priori estimate of the stability for the difference scheme (3.3), we formulate the following statement.

Lemma 3.1. The operator $\tilde{A}$ is subjected to the operator $A$

$$
\|\tilde{A} y\|^{2} \leq 2 \alpha^{2}(A y, y)
$$

where $\alpha=\max \left\{\alpha_{1}, \alpha_{2}\right\}, \alpha_{k}=\max _{\omega_{h}}\left|h_{k}^{*}\right|, k=1,2, \alpha<H / 3, H=\max \left\{H_{1}, H_{2}\right\}$.

Theorem 3.2. The following estimate is valid

$$
\left\|y_{n+1}\right\|_{A}^{2} \leq\left\|u_{0}\right\|_{A}^{2}+9 \sum_{k=1}^{n} \tau\left\|\varphi_{k}\right\|^{2}
$$

in an arbitrary computational domain under the condition $\tau>\frac{9 \alpha^{2}}{4(\sigma-0,5)}, \sigma>$ 0,5 .

Proof . Using Lemmas 1.1, 3.1 we get the following constants for the conditions of Theorem 3.1: $c_{1}=2, \alpha=H / 3, c_{2}=5 / 9$. If $\varepsilon_{1}=2 / 9, \varepsilon_{2}=1 / 18$, then we get the required estimate.

Remark 3.1. In the case of the rectangular computational domain which is covered by a uniform orthogonal grid, we have $\alpha=0, c_{2}=1$, and the difference scheme (3.3) is stable for any $\tau, h$.

Remark 3.2. If $\sigma=0$, then the a priori estimate of the stability for the difference scheme (3.3) can not be obtained.

Remark 3.3. Since Theorem 3.1 was proved without limitations on dimension of problem, then analogous results can be obtained also for multi-dimensional parabolic equations. 


\section{NUMERICAL EXPERIMENTS}

The properties of the proposed scheme were examined by solving a number of tests. The comparison was made with the well-known finite-difference schemes:

$$
\begin{gathered}
\sum_{\alpha=1}^{2} y_{\bar{x}_{\alpha} \hat{x}_{\alpha}}=-f(\mathbf{x}), \quad \mathbf{x} \in \omega, \\
\sum_{\alpha=1}^{2} \frac{y_{x_{\alpha}}-y_{\bar{x}_{\alpha}}}{H_{\alpha}}=-f(\mathbf{x}), \quad \mathbf{x} \in \omega .
\end{gathered}
$$

Difference equation (4.1) approximates equation (2.1) with the first order at the near-boundary points and with the second order at the interior nodes [1]. Difference equation (4.2) does not approximate differential equation at the near-boundary nodes. Both difference schemes (4.1), (4.2) have the second order of convergence [1]. The computation domain is shown in fig. 3.

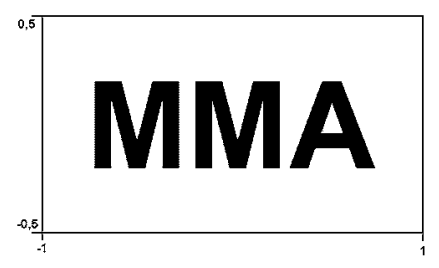

Figure 3. The computation domain.

We take the exact solution of problem (2.1), (2.2) as by

$$
u(\mathbf{x})=\exp \left(x_{1}\right)+\exp \left(x_{2}\right) .
$$

The data on the relative global error of the discrete solution and normal derivatives at the near-boundary points are presented in the table. The calculation time on the largest grid was about 15 minutes using a standard PC.

The new scheme allows us to obtain essentially better accuracy on the coarse grids. The solution has a high accuracy near the boundary. A local error has the maximum value inside the computation domain, but not at near-boundary points. 
Table 1.

The plobal error $\varepsilon$ and the error of the derivative $\varepsilon_{n}$.

\begin{tabular}{rcccccc}
\hline $\mathrm{N}$ & \multicolumn{5}{c}{$\varepsilon$} & $\varepsilon_{n}$ \\
\hline & $\mathrm{O}(1)$ & $\mathrm{O}(\mathrm{h})$ & $\mathrm{O}\left(\mathrm{h}^{2}\right)$ & $\mathrm{O}(1)$ & $\mathrm{O}(\mathrm{h})$ & $\mathrm{O}\left(\mathrm{h}^{2}\right)$ \\
\hline & & & & & & \\
$12 \times 12$ & 0,012311 & 0,012297 & 0,013764 & 3,2364 & 3,2508 & 0,1469 \\
$25 \times 25$ & 0,006167 & 0,006220 & 0,004571 & 1,2240 & 1,3547 & 0,0524 \\
$50 \times 50$ & 0,002503 & 0,002411 & 0,001062 & 0,5541 & 0,4769 & 0,0271 \\
$100 \times 100$ & 0,001178 & 0,001205 & 0,000301 & 0,1450 & 0,1739 & 0,0150 \\
$200 \times 200$ & 0,000280 & 0,000279 & 0,000076 & 0,1997 & 0,2014 & 0,0082 \\
$400 \times 400$ & 0,000071 & 0,000072 & 0,000009 & 0,1549 & 0,1641 & 0,0042 \\
\hline
\end{tabular}

\section{REFERENCES}

[1] A.A. Samarskii. Theory of difference schemes. Nauka, Moskow, 1989. (in Russian)

[2] A.A. Samarskii, P.N. Vabishchevich, and P.P. Matus. Difference schemes with operator factors. ZAO TSOTZH, Minsk, 1998. (in Russian)

[3] A.A. Samarskii, P.N. Vabishchevich and P.P. Matus. Difference schemes of high order of precision on irregular grids. Differents. Urav., 32 (2), 1996, 265 - 274. (in Russian)

[4] A.A. Samarskii, P.N. Vabishchevich, and P.P. Matus. Difference schemes of second order of approximation on irregular grids. Journal Vychisl. Matem. i Matyem. Phys., 38 (3), 1998, 413 - 424. (in Russian)

[5] A.A. Samarskii, P.N. Vabishchevich, P.P. Matus, and A.N. Zyl. Difference schemes of high order of approximation for Dirichlet problem in an arbitrary area. Doklady NAN Belarusi, 42 (1), 1998, 13 - 17. (in Russian)

[6] A.A. Samarskii, P.N. Vabishchevich, P.P. Matus and A.N. Zyl. Difference Schemes of Second Order of Approximation for Multidimensional Elliptic Equations in Arbitrary Area. In: Proc. of the Intern. Conference FDM, Russe, Bulgaria, 1997, Finite-Difference Methods: Theory and Application, A. A. Samarskii, Lubin G. Vulkov, and Petr N. Vabishchevich (Eds.), NOVA Science Publishers, 1999.

[7] A.N. Zyl. Construction of difference schemes of high order of precision for Dirichlet problem in arbitrary areas. In: Proc. of the 2nd Intern. Conference CFDM98, Minsk, Belarus, 1998, Finite-Difference Methods: Theory and Application, A.A. Samarskii (Eds.), Institute of Mathematics of NAS of Belarus, 1998, Vol. 3, $147-151$.

\section{DIDELIO TIKSLUMO BAIGTINIU SKIRTUMU SCHEMOS}

\section{P.P. MATUS, A.N. ZYL}

Darbe nagrinëjami matematinès fizikos uždaviniai, kai apibrēžimo srities kontūras yra bet kokia glodi uždara kreivè. Ši sritis pakeičiama tolygiu stačiakampiu tinklu. Panaudojant specialias aproksimavimo formules ir pasienio taškuose aproksimacijos paklaidos eilè yra antroji. Svarbi naujojo algoritmo savybė yra tai, kad visuose taškuose naudojamas toks pat diskrečiojo tinklo šablonas. İrodomi aprioriniai stabilumo izverčiai ir ỉvertinamas diskrečiojo sprendinio konvergavimo greitis. Pateikti skaičiavimo eksperimento, kuriame naujoji schema palyginama su dviem kitomis žinomomis baigtinių skirtumų schemomis, rezultatai. 